\title{
Comparison of high resolution melting analysis, pyrosequencing, next generation sequencing and immunohistochemistry to conventional Sanger sequencing for the detection of p.V600E and non-p.V600E BRAF mutations
}

Michaela Angelika Ihle ${ }^{1 *}$, Jana Fassunke ${ }^{1}$, Katharina König ${ }^{1}$, Inga Grünewald ${ }^{1,4}$, Max Schlaak ${ }^{2}$, Nicole Kreuzberg ${ }^{2}$, Lothar Tietze ${ }^{3}$, Hans-Ulrich Schildhaus ${ }^{1,5}$, Reinhard Büttner ${ }^{1}$ and Sabine Merkelbach-Bruse ${ }^{1}$

\begin{abstract}
Background: The approval of vemurafenib in the US 2011 and in Europe 2012 improved the therapy of not resectable or metastatic melanoma. Patients carrying a substitution of valine to glutamic acid at codon 600 (p.V600E) or a substitution of valine to leucine (p.V600K) in BRAF show complete or partial response. Therefore, the precise identification of the underlying somatic mutations is essential. Herein, we evaluate the sensitivity, specificity and feasibility of six different methods for the detection of BRAF mutations.

Methods: Samples harboring p.V600E mutations as well as rare mutations in BRAF exon 15 were compared to wildtype samples. DNA was extracted from formalin-fixed paraffin-embedded tissues by manual micro-dissection and automated extraction. BRAF mutational analysis was carried out by high resolution melting (HRM) analysis, pyrosequencing, allele specific PCR, next generation sequencing (NGS) and immunohistochemistry (IHC). All mutations were independently reassessed by Sanger sequencing. Due to the limited tumor tissue available different numbers of samples were analyzed with each method $(82,72,60,72,49$ and 82 respectively).

Results: There was no difference in sensitivity between the HRM analysis and Sanger sequencing (98\%). All mutations down to $6.6 \%$ allele frequency could be detected with 100\% specificity. In contrast, pyrosequencing detected $100 \%$ of the mutations down to $5 \%$ allele frequency but exhibited only $90 \%$ specificity. The allele specific PCR failed to detect $16.3 \%$ of the mutations eligible for therapy with vemurafenib. NGS could analyze $100 \%$ of the cases with 100\% specificity but exhibited $97.5 \%$ sensitivity. IHC showed once cross-reactivity with p.V600R but was a good amendment to HRM.
\end{abstract}

Conclusion: Therefore, at present, a combination of HRM and IHC is recommended to increase sensitivity and specificity for routine diagnostic to fulfill the European requirements concerning vemurafenib therapy of melanoma patients.

Keywords: HRM, cobas $^{\circledast}$ BRAF V600 test, therascreen ${ }^{\circledast}$ BRAF pyro kit, Immunohistochemistry, Next generation sequencing, BRAF mutational analysis

\footnotetext{
* Correspondence: michaela.ihle@uk-koeln.de

${ }^{1}$ Institute of Pathology, University of Cologne, Medical Centre, Cologne,

Germany

Full list of author information is available at the end of the article
} waiver (http://creativecommons.org/publicdomain/zero/1.0/) applies to the data made available in this article, unless otherwise stated. 


\section{Background}

The v-raf murine sarcoma viral oncogene homolog B1 $(B R A F)$ is one of three $R A F$ genes (rapidly accelerated fibrosarcoma A, B, C) localized on chromosome 7q34. This gene encodes a cytoplasmic serine-threonine protein kinase of the RAF family. RAF kinases are part of the mitogen-activated protein (MAP) kinase pathway involved in cell growth, survival and differentiation [1].

$B R A F$ mutations play an important role in $40-70 \%$ of malignant melanomas, $45 \%$ of papillary thyroid cancers and $10 \%$ of colorectal cancers besides ovarian, breast and lung cancers [2-4].

According to the COSMIC database (Catalogue Of Somatic Mutations In Cancer, Dec 2013 [5]) 44\% of the melanomas harbor $B R A F$ mutations and $97.1 \%$ of these mutations are localized in codon 600 of the $B R A F$ gene [6]. The most common variation is a substitution of valine to glutamic acid at codon 600 (c.1799 T $>$ A, p.V600E or c.1799_1800TG > AA, p.V600E2; frequency 84.6\%). Less common mutations are substitutions of valine to lysine (c.1798_1799GT > AA, p.V600K; frequency 7.7\%), to arginine (c.1798_1799GT > AG, p.V600R; 1.0\%), to leucin (c.1798G > A, p.V600M; 0.3\%) or to aspartic acid (c.1799_1780TG > AT, p.V600D; 0.1\%), mutations affecting codon 597 (p.L597; 0.5\%), codon 594 (p.D594; 0.4\%) and mutations in codon 601 resulting in the exchange of lysine to glutamic acid (c.1801A > G, p.K601E; 0.7\%).

The approval of vemurafenib (PLX 4032, Roche Molecular Systems, Pleasanton, CA) in the US 2011 and in Europe 2012 improved the therapy of not resectable or metastatic melanoma. Vemurafenib exhibits an approximately 30-fold selectivity for p.V600E mutated compared to wildtype $B R A F$ melanomas. In addition, patients carrying a p.V600K mutation included in the BRIM-3 study showed response to this inhibitor [7]. In a phase I trial, a $70 \%$ response rate to vemurafenib among 32 genotype selected metastatic melanoma patients was observed [8]. Recent in vitro and in vivo experiments indicate that vemurafenib might have an effect in patients with rare mutations in codon 600 of the BRAF gene [9-11] as for instance p.V600D or p.V600R [12,13]. Furthermore, dabrafenib (GSK2118436), another selective BRAF inhibitor [14] shows good clinical response rates not only for patients with p.V600E or p.V600K mutations but also in patients carrying a p.V600R, p.V600M or a double p.[V600E(;)V600M] mutation [15,16] giving new therapy options for melanoma patients with rare $B R A F$ mutations.

The FDA approved vemurafenib with the $\operatorname{cobas}^{\oplus} B R A F$ V600 test (Roche) as companion diagnostic tool. The European Medicine Agency`s (EMA) Committee for Human Medicinal Products (CHMP) approved vemurafenib in February 2012 with two main differences to the FDA approval: a companion diagnostic test was not defined and treatment option is given for patients with melanomas carrying any mutation in codon 600 of the BRAF gene. Because a mutation in codon 600 determines eligibility for $B R A F$ inhibitor treatment, several molecular screening methods have been developed. However, the level of validation and characterization of the performance features is not defined.

The aim of this study was to evaluate several parameters such as sensitivity and feasibility of different methods for the $B R A F$ mutation analysis. Here, we compare the allele specific PCR done by the cobas ${ }^{\oplus} B R A F$ V600 test, the pyrosequencing using the therascreen ${ }^{\circledR}$ BRAF Pyro Kit (Qiagen), the high resolution melting (HRM) analysis, the immunohistochemistry (IHC), the next generation sequencing (NGS) approach and the bidirectional Sanger sequencing with regard to their sensitivity, specificity, costs, amount of work, feasibility and limitations. To our knowledge, this is the only study comparing these five PCR-based methods with IHC.

\section{Methods \\ Samples}

A total of 82 tumor samples were collected in the years 2010 until 2013 under approved ethical protocols complied with the Ethics Committee of the University of Cologne (Germany) and with informed consent from each patient. Of these, 63 samples were melanomas, 11 were lung adenocarcinomas and eight were colorectal carcinomas.

Tumors were diagnosed by an experienced pathologist (H. U. S., L. T.) and tumor content and pigmentation were defined. All samples were analyzed with Sanger sequencing as gold standard and the in-house method high resolution melting (HRM) analysis. The other methods were evaluated with a smaller number of samples due to the limited amount of tumor tissue available. Special attention was paid to the fact that each mutation type was once analyzed with each method. Overall 40 samples were at least analyzed with each of the six evaluated methods.

\section{DNA isolation}

All samples were fixed in neutral-buffered formalin prior to paraffin embedding (FFPE-samples). On a haematoxylineosin stained slide tumor areas were selected by a pathologist (H.U.S.) and DNA was extracted from corresponding unstained $10 \mu \mathrm{m}$ thick slides by manual micro-dissection. The DNA was isolated by automated extraction using the BioRobot M48 (Qiagen, Hilden, GER) following the manufacturer's protocols. Quality and quantity of isolated DNA was assessed by agarose gel electrophoresis, by a Nanodrop 2000c spectrophotometer (PeqLab, Erlangen, GER) or in the case of next generation sequencing with the Qubit ${ }^{\circ}$ Fluorometer (Life Technologies, Carlsbad, USA). 


\section{High resolution melting analysis}

High resolution melting (HRM) analysis was set up using $10 \mathrm{ng}$ of genomic DNA, $3.5 \mathrm{mM} \mathrm{MgCl} 2$, $1 \times$ LightCycler 480 High Resolution Melting Master and $200 \mathrm{nM}$ of each primer in a final reaction volume of $20 \mu \mathrm{l}$. Primer sequences were as follows: forward 5'- ATG CTT GCT CTG ATA GGA AAA TGA -3' and reverse 5'- ATC CAG ACA ACT GTT CAA ACT -3' with an annealing temperature of $59^{\circ} \mathrm{C}$. Analyses were performed in duplicates using the LightCycler 480 platform (Roche Diagnostics, Mannheim, GER). Each run included a wildtype control and a mutant, p.V600E, control for normalization. Results were analyzed by Gene Scanning software with normalized, temperature-shifted melting curves displayed as difference plot. Samples showing a melting behavior differing from the wildtype control but not that of a mutant sample were considered as borderline samples. These samples were retested by direct Sanger sequencing of HRM products.

\section{Sanger sequencing}

Sanger sequencing was performed on the same amplicons as used for HRM analysis. $5 \mu \mathrm{l}$ of PCR products were purified with exonuclease I and Fast-AP (Thermo Fisher Scientific, Waltham, USA) for $15 \mathrm{~min}$ at $37^{\circ} \mathrm{C}$ and $15 \mathrm{~min}$ by $80^{\circ} \mathrm{C}$. A sequencing reaction was set up with $1 \mu$ of purified PCR products and the BigDye ${ }^{\odot}$ Terminator v1.1 Cycle Sequencing Kit (Life Technologies) following the manufacturer's instructions. The BigDye XTerminator ${ }^{\circledR}$ Purification Kit (Life Technologies) was used for the purification of the DNA sequencing reactions removing non-incorporated BigDye ${ }^{\odot}$ terminators and salts. Solution was incubated for $30 \mathrm{~min}$ with agitation of $1800 \mathrm{rpm}$. Sequencing analyses were carried out on the eight capillary 3500 Genetic Analyzer (Life Technologies).

\section{Next generation sequencing}

Targeted next generation sequencing (NGS) was performed on 72 FFPE samples. Isolated DNA $(<0.5-$ $97.6 \mathrm{ng} / \mu \mathrm{l})$ was amplified with an in-house specified, customized Ion AmpliSeq Primer Pool. The panel comprises 102 amplicons of 14 different genes including exon 11 and 15 of the BRAF gene. PCR products were ligated to adapters and enriched for target regions using the Ion AmpliSeq Panel ${ }^{\mathrm{TM}}$ Library kit according to manufacturer's instructions (Life Technologies). The generated libraries were equimolar pooled for amplicon sequencing to a concentration of $20 \mathrm{nM}$ of each sample to counterbalance differences in sample quality. Sequencing was performed on an Illumina MiSeq benchtop sequencer (Illumina, San Diego, USA). Results were visualized in the Integrative Genomics Viewer (IGV) [6] and manually analyzed. A 5\% cutoff for variant calls was used and results were only interpreted if the coverage was $>100$.

\section{Pyrosequencing}

Pyrosequencing was performed with the therascreen ${ }^{\circ}$ BRAF Pyro Kit (Qiagen) detecting certain mutations in codon 600 of the BRAF gene according to manufacturer's instructions. $1 \mu \mathrm{l}$ of each isolated DNA was analyzed per run. Pyrosequencing was performed on the PyroMark Q24 platform (Qiagen) using the PyroMark Gold Q24 reagents. Pyrograms were generated with the PyroMark Q24 software (v. 2.0.6.) and data were analyzed manually or with a plug-in tool provided by Qiagen. Sequences surrounding the site of interest served as normalization and reference peaks for quantification and quality control. Dispensation order was as follows: 5'GCT ACT GTA GCT AGT ACG AAC TCA-3'. Two different "sequence to analyze" were used: 5'- YAY TGT AGC TAG ACS AAA AYC ACC -3' or 5'- CHC TGT AGC TAG ACS AAA ATY ACC -3' for manual analysis. Samples with $5 \%$ mutated alleles or more were scored as mutation positive.

\section{Allele specific PCR}

For the allele specific PCR the $\operatorname{cobas}^{\ominus} B R A F$ V600 test was utilized. DNA was isolated with the in-house method. Following the manufacturer's instructions, $5 \mathrm{ng} / \mu \mathrm{l}$ DNA of each sample were analyzed on the $\operatorname{cobas}^{\ominus} \mathrm{z} 480$ system. If the concentration of the extracted DNA was too low, the maximum DNA volume of $25 \mu \mathrm{l}$ was used. The results were displayed automatically as report by the $\operatorname{cobas}^{\oplus} \mathrm{z} 480$ software.

\section{Immunohistochemistry}

Anti-BRAF p.V600E immunohistochemical staining was performed using the specific monoclonal mouse antibody VE1 (Spring Bioscience, Pleasanton, CA, USA; purchased from Zytomed Systems, Berlin, Germany). Dewaxing, heat induced epitope retrieval with citrate buffer, antibody incubation (dilution 1:50) and counterstaining were carried out on a BOND Max immunostainer by using Bond Epitope Retrieval Solution 1 and the Bond Polymer Refine Detection kit (Menarini, Berlin, Germany). Immunohistochemical staining was carried out within 2 weeks after cutting the $4 \mu \mathrm{m}$ sections.

Staining results were scored from 0 to $3+$ by a senior pathologist (H. U. S. or I. G.) blinded to the results of molecular analysis. The staining was considered as positive for p.V600E staining $(2+$ and $3+)$ when the majority of viable tumor cells showed clear cytoplasmic staining. Negative staining results were interpreted when there was no or only slight staining, staining of only single cells or of monocytes and macrophages (0 and $1+)$. 


\section{Results and discussion}

Precise identification of genomic alterations is essential for personalized therapy in cancer. Concerning melanoma, particularly patients carrying a mutation in codon 600 of the $B R A F$ gene respond to vemurafenib $[7,17]$. As no companion diagnostic test for this drug is prescribed in Europe, we aimed at evaluating a sensitive and specific molecular method for $B R A F$ mutation analysis by comparing high resolution melting (HRM) analysis, pyrosequencing (therascreen ${ }^{\circ}$ BRAF Pyro Kit (Qiagen)), allele specific PCR (cobas ${ }^{\circ}$ BRAF V600 test (Roche)), Sanger sequencing, next generation sequencing (NGS) and immunohistochemistry (IHC).

82 tumor samples (63 melanomas, 11 lung adenocarcinomas and eight colorectal carcinomas) evaluated during routine diagnostics from 2010 - 2013 and covering a wide range of different mutations as well as wildtype samples were subjected to analysis. Because of limited tumor tissue available we were not able to analyze all samples with each method but we paid attention to the fact that each mutation type was once analyzed with each method. At least, 40 samples were analyzed with all six evaluated methods. Lung adenocarcinomas as well as colorectal carcinomas were included into this study to get a broader spectrum of mutations. Hereby, the frequency of mutations other than p.V600E is significantly higher than in melanoma [18-20]. BRAF mutations were mainly found in codon 600 , codon 469 and codon 594 of non-small-cell lung cancer (NSCLC) samples [21]. Furthermore, therapies targeting $B R A F$ mutant tumors have recently been identified in NSCLC [22,23].

Tumor content and pigmentation was assessed by an experienced pathologist (H. U. S. or I. G.). The proportion of tumor cells ranged from $15-100 \%$ (Additional file 1) and pigmentation was scored as no ( $<5 \%$ of evaluated melanoma cells), low $(5-49 \%)$ and high pigmentation ( $>50 \%)$.

\section{High resolution melting analysis and Sanger sequencing}

Using the high resolution melting (HRM) method and Sanger sequencing, 81 of 82 samples could be amplified (Additional file 1) and analyzed using the same PCR products. Cases were considered as mutated using HRM if a significant difference of the fluorescence level was detected that was outside the range of variation of the wildtype control. Samples in between wildtype control and a mutant melting behavior were considered as borderline results. All mutated as well as borderline samples were subjected to Sanger sequencing to determine the specific mutation type. The assay was set up with an amplicon of 163 base pairs and is therefore able to detect all hotspot mutations as well as rare mutations in the entire exon 15 (codon 582 to 620) of BRAF (specificity 100\%). This is in concordance with the studies of Colomba et al. [24] and Tol et al. [25]. Figure 1 displays representative difference plots for BRAF p.V600E (D), p.V600K (E) and p.V600R (F) mutations. p.V600E mutation (control, shown in red) can be clearly distinguished from p.V600K mutation (shown in green) and p.V600R (shown in blue). Furthermore, electropherograms with common mutations in codon 600 of the $B R A F$ gene analyzed by Sanger sequencing are shown: p.V600E (A), p.V600K (B) and p.V600R (C).

Only one sample with p.V600E mutation could neither be analyzed by Sanger sequencing nor by HRM because of amplification failure (1.2\%). Others have shown, that melanin binds to and interferes with DNA polymerases resulting in invalid test results [26]. But this case had a tumor content of $80 \%$ and showed no pigmentation. Therefore, the failure of amplification of the $163 \mathrm{bp}$ fragment for Sanger sequencing and HRM is rather due to the high degradation of FFPE-used material than to pigmentation. This high degradation of FFPE used material can also explain the higher Sanger sequencing failure rate described in other studies using a larger PCR product for analysis [24,27].

The sensitivity of Sanger sequencing is described in the literature as $20 \%$ mutated alleles in a background of wildtype alleles [28], but in the present study, we were able to detect $6.6 \%$ mutated alleles (Table 1, Additional file 1). Figure 2 shows six electropherograms of samples analyzed in this study with different allele frequencies according to next generation sequencing (A: $0 \%, \mathrm{~B}: 6.6 \%$, C: 15\%, D: $33 \%$, E: $62 \%$ and F: $87 \%$ ). B) shows that a sample with $6.6 \%$ allele frequency can be distinguished from a wildtype sample (A) and that an allele frequency of $15 \%$ can be clearly detected as p.V600E mutation using Sanger sequencing. HRM analysis has an even lower detection limit of $6.3 \%$ mutated alleles as reported by our group previously [29]. Carbonell et al. showed an even lower detection limit ranging from $1-5 \%$ [27]. This was also supported by Balic et al. [30] who showed that analyzing DNA methylation 1\% methylated DNA in the background of unmethylated DNA could be reproducibly detected in fresh frozen as well as in FFPE samples.

99\% of all mutations could be detected by HRM as well as by Sanger sequencing. Case 30 could be amplified and was wildtype using Sanger sequencing, HRM and the cobas $^{\circ}$ BRAF V600 test but exhibited a p.V600E $B R A F$ mutation with an allele frequency between 5 and $2 \%$ using pyrosequencing and NGS. Immunohistochemistry was scored positively as $2+$. Tumor content of this sample was $30 \%$ with a high pigmentation rate (case 30, Figure 3, Additional file 1). At least for Sanger sequencing, it was already reported that the tumor content may have influence on the sensitivity. Tol et al. demonstrated that the analysis of tumor samples containing more than $30 \%$ percent of tumor cells increased the sensitivity of 


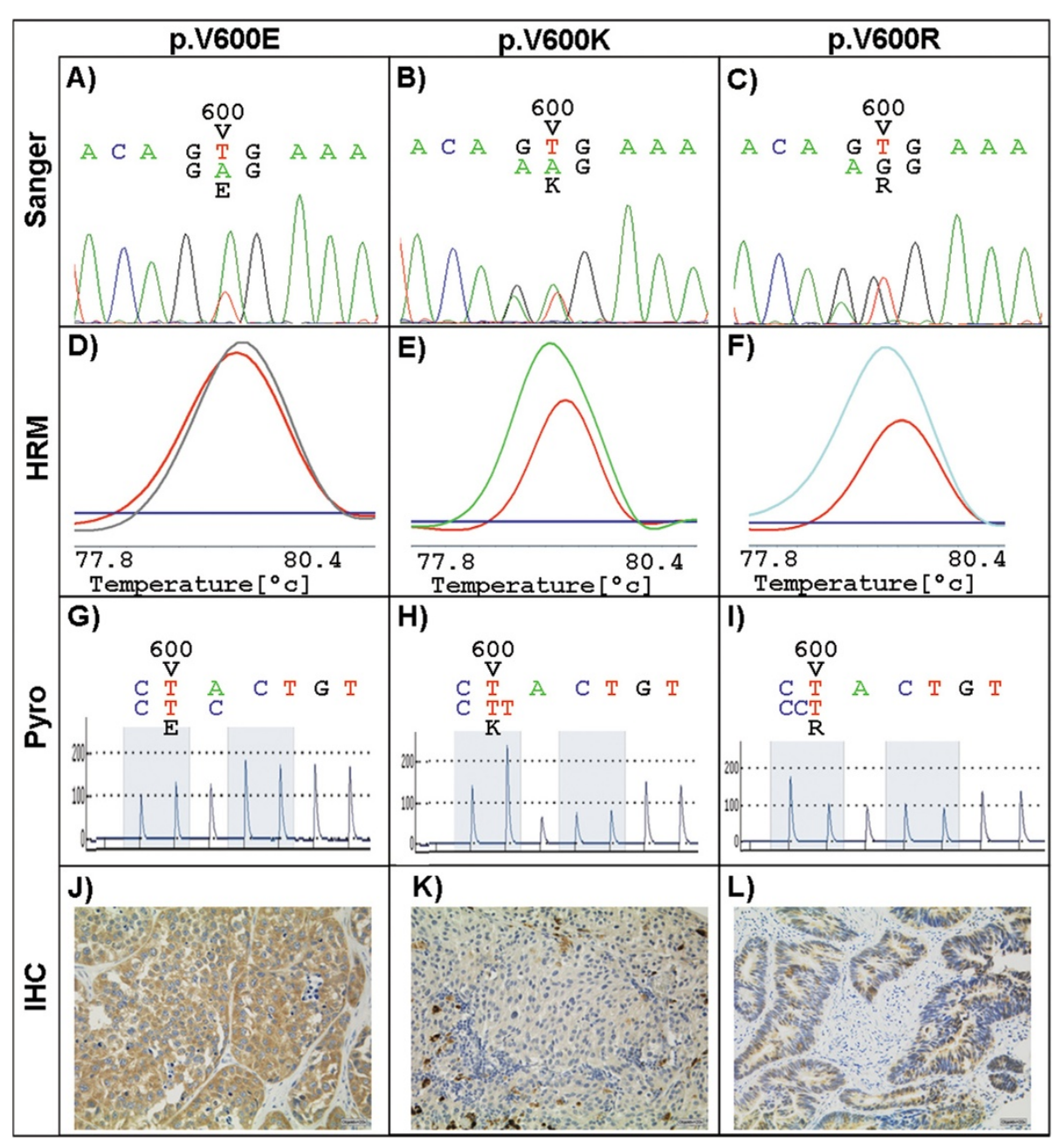

Figure 1 Representative results for BRAF exon 15 mutation analysis. Sanger sequencing (A - C), high resolution melting (HRM) analysis (D - F), pyrosequencing (Pyro) (G - I) and immunohistochemistry (IHC) (J-L) are compared: The first column shows exemplarily p.V600E mutations, the second p.V600K mutations and the third column p.V600R mutations. In HRM, normalized and temperature shifted difference plots showing wildtype control in blue and mutant control in red. HRM can distinguish between p.V600E (red) and p.V600K (green) and p.V600R (light blue). Pyrosequencing was performed in the reverse direction with the sequence to analyze 5'- YAY TGT AGC TAG ACS AAA AYC ACC -3'. All three mutations can be detected. Immunohistochemistry shows a strong staining for p.V600E (J) but is negative for p.V600K (K) in representative melanoma sample. Pigmentation has to be clearly distinguished from a positive p.V600E staining (K). Cross reactivity was observed for p.V600R mutation (L) in a colorectal carcinoma sample. A: adenine, C: cytosine, G: guanine, T: thymine, V: valine, E: glutamic acid, K: lysine, R: arginine.

Table 1 Summary of the properties of the evaluated methods

\begin{tabular}{|c|c|c|c|c|c|c|}
\hline & HRM & Pyro & Cobas & IHC & NGS & Sanger \\
\hline CE mark & No & No & Yes & No & No & No \\
\hline Limit of detection [\%] & 6.6 & 5 & 7 & 5 & 2 & 6.6 \\
\hline Detection of rare mutations & Yes & Yes- downstream of codon 600 & No- 4 different mutations & No- p.V600E & Yes & Yes \\
\hline Specificity [\%] & 100 & 90 & 98.3 & 98 & 100 & 100 \\
\hline Turnaround time & 1 day & 2 days & 1 day & 1 day & $3-5$ days & $2-3$ days \\
\hline Costs & Low & High & Medium & Low & Very high & Medium \\
\hline
\end{tabular}

HRM: high resolution melting analysis; Pyro: pyrosequencing with the therascreen ${ }^{\circledR}$ BRAF Pyro Kit; cobas: cobas ${ }^{\oplus}$ BRAF V600 test; IHC: immunohistochemistry; NGS: next generation sequencing on the MiSeq platform; Sanger: Sanger sequencing. 


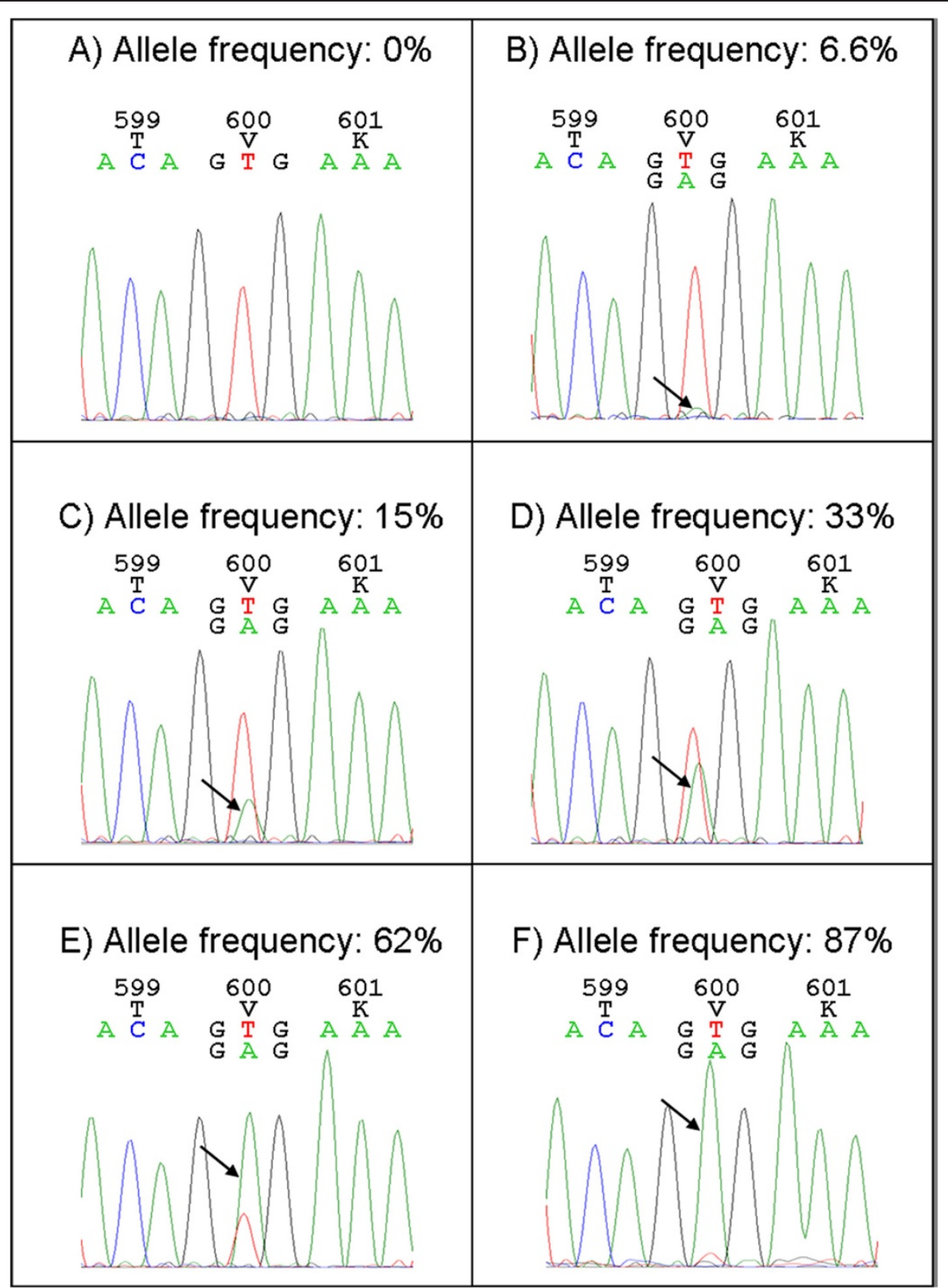

Figure 2 BRAF p.V600E mutation analysis of formalin-fixed paraffin-embedded tumor samples using Sanger sequencing. Electropherograms showing that Sanger sequencing is not only able to detect mutations with high mutant allele frequency (D - F) but also mutations with rather low mutant allele frequency (B and C) compared to a wildtype sample (A). Even 6.6\% of BRAF p.V600E allele could be detected. A: adenine, C: cytosine, G: guanine, T: thymine, T: threonin, V: valine, K: Iysine.

Sanger sequencing in a cohort of 511 primary colorectal cancer samples [25].

Case 67, showing twice a borderline result in HRM, revealed a substitution from guanine to adenine in only one of four Sanger sequencing reactions. The $\operatorname{cobas}^{\circ} B R A F$ V600 test was also negative. Therefore, this substitution was considered to be a fixation artifact and the case was classified as wildtype. A pitfall of all PCR based methods amplifying DNA from FFPE tissues is this occurrence of fixation artifacts [31,32]. To exclude such false-positive results, we highly recommend performing PCR amplification in duplicates prior to mutation analysis.

\section{Pyrosequencing}

Pyrosequencing is a real-time sequencing by synthesis approach and allows the quantification of mutated alleles. The therascreen ${ }^{\circ}$ BRAF Pyro Kit for exon 15 of $B R A F$ is specific for mutations in codon 600 with a 


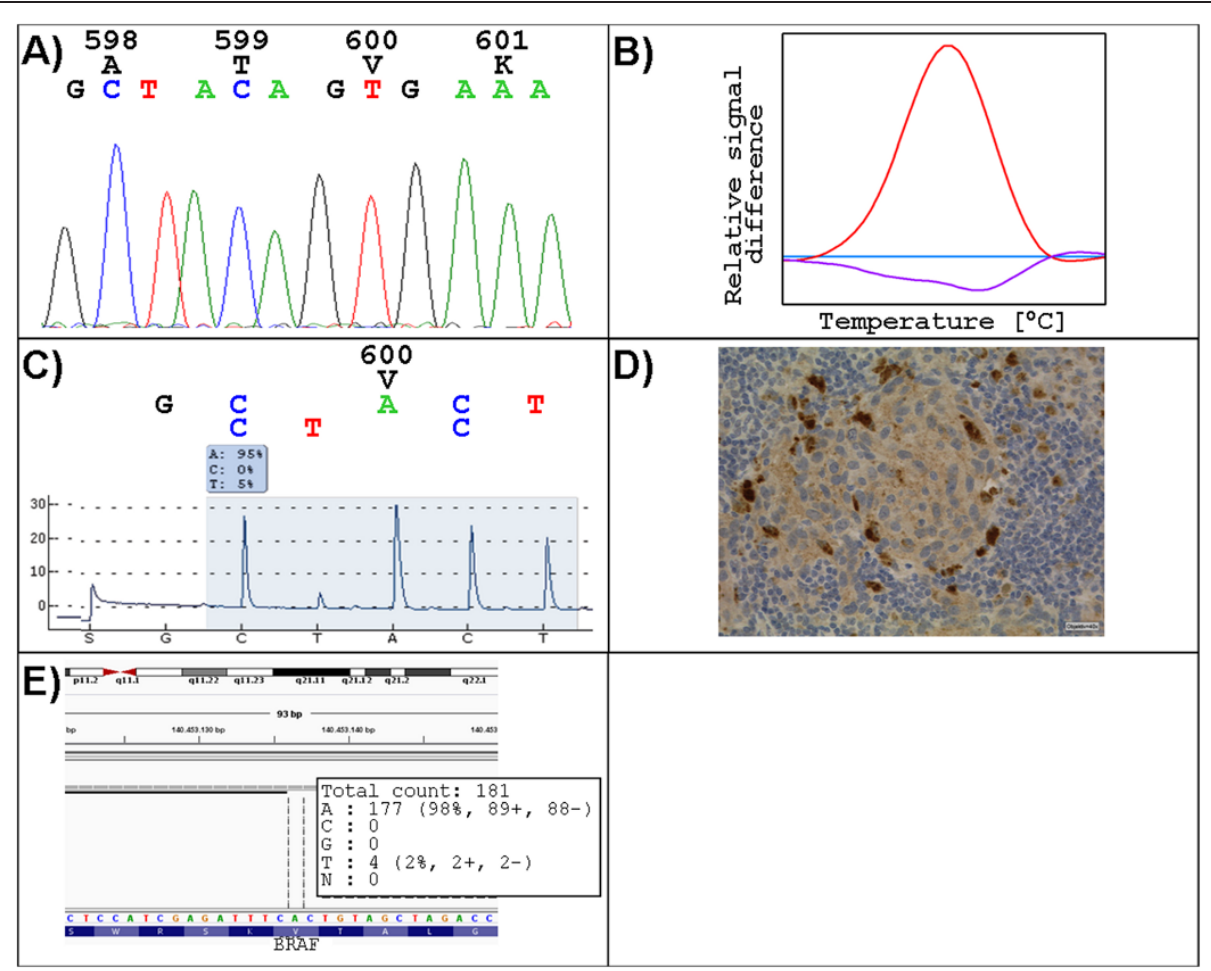

Figure 3 Melanoma sample showing different results of the BRAF p.V600E mutational analysis (case 30). Sanger sequencing as well as high resolution melting analysis show wildtype results (A and $\mathbf{B}$, respectively). Pyrosequencing analysis resulted in a p.V600E mutation with a $5 \%$ mutant allele frequency having low relative fluorescent units of almost 30 (C). This result is confirmed by immunohistochemistry (D). Next generation sequencing resulted in a $2 \%$ mutant allele frequency with a coverage rate of 181 (E).

reported sensitivity for $\mathrm{p} . \mathrm{V} 600 \mathrm{E}$ of $2 \%$ mutated alleles in a background of wildtype alleles according to manufacturer's reference. In addition, recent reports show that even rare mutations in codon 600 can be detected using pyrosequencing with a customer designed assay set up [24,33]. In our preselected cohort the minimum of mutated alleles detected with pyrosequencing was 5\% (Table 1 and Additional file 1). This is in concordance with Tsiatis et al. showing as well a detection limit of 5\% for pyrosequencing [34]. All 72 samples were successfully amplified and subjected to analysis. The PCR product has an estimated size of approximately 120 base pairs. Figure 1 shows representative pyrograms of BRAF p.V600E (G), p.V600K (H) and p.V600R (I) mutations. Only pyrograms showing peak heights of $>/=30$ relative fluorescent units (RLU) were evaluated. Result interpretation was once performed by visual inspection with different sequences to analyze and in some samples with a mutation in codon 600 using the provided plug-in tool (Qiagen).

Concerning the p.V600E mutation pyrosequencing showed a higher sensitivity than Sanger sequencing. Pyrosequencing detected the p.V600E mutation down to $5 \%$ mutated alleles in a background of wildtype alleles but with values for the relative fluorescent units close to our threshold of 30. Sanger sequencing, HRM and the cobas ${ }^{\oplus}$
$B R A F$ V600 test failed to detect this mutation as described above. Immunohistochemistry was scored positively as $2+$. Interestingly, NGS showed a $2 \%$ allele frequency for p.V600E in this case being under the cutoff defined for our study (case 30).

The therascreen ${ }^{\oplus}$ BRAF Pyro Kit sequences in the reverse direction starting at codon 600 of the BRAF gene. Therefore, mutations downstream of codon 600 will be identified either as false-negative wildtype samples or as false-positive p.V600E samples. According to COSMIC database (Catalogue of Somatic Mutations in Cancer, Dec 2013) $1.4 \%$ of mutations are consequently not detected [6]. In our study, three cases were falsely detected as p.V600E mutation showing once a p.K601E, once a p.V600K and once a p.[V600E(;)K601E] double mutation using Sanger sequencing and NGS (case 41, 36 and 25, respectively, Additional file 1). If these patients are treated with vemurafenib they may develop keratocanthoma and squamous-cell carcinoma caused by treatment with supposable limited clinical benefit $[35,36]$.

Furthermore, as the read length of the pyrosequencing kit is optimized for the detection of p.V600E mutation, the peak height can be misinterpreted in the regions upstream of codon 600. Two cases that were wildtype using Sanger sequencing and NGS and showed borderline results 
in HRM exhibited a p.G596 mutation using pyrosequencing with a mutation frequency of 8 and 14\% (case 29 and 39, Additional file 1) analyzed by the first sequence to analyze. A third case (case 31, Additional file 1) could not be amplified by Sanger sequencing and HRM but was p.G596R mutated using pyrosequencing ( $7 \%$ allele frequency). Computed analysis with a second sequence to analyze of all three samples showed no mutation in the pyrograms reinforcing the wildtype result of the other methods. A further case (case 32) exhibited a p.L597R mutation using Sanger sequencing and NGS (8\% allele frequency) but the pyropgram showed a p.G596R mutation with an allele frequency of $28 \%$. The sequence to analyze and the dispension order used are not designed to detect mutations in codon 597. The mutated nucleotide is therefore incorporated at the wrong position of the pyrogram resulting in an incorrect mutation calling.

Thus, pyrosequencing showed a specificity of $90 \%$ for the detection of all mutations in our preselected cohort (Table 1). According to the manufacturer the therascreen ${ }^{\circ}$ BRAF Pyro Kit should only be used for mutations in codon 600 of the human $B R A F$ gene. Regarding only the hotspot codon 600 pyrosequencing exhibited a specificity of $94.6 \%$.

If using the therascreen ${ }^{\circ}$ BRAF Pyro Kit for the detection of additional mutations the results should be critically considered especially concerning mutations in codon 597, 596 and 594 of the BRAF gene. This is in concordance with Gong et al., 2010 showing continuous loss of signal intensities using pyrosequencing when sequencing towards increased read length [37]. Moreover, the interpretation of complex mutations (e.g. double mutations) is prone to errors as only the ratio of the peak heights vary. In the study of Shen and Qin (2012) a p.V600K mutation was overlooked by visual inspection but was detected using pyrosequencing data analysis software [38]. Using software tools and a customer designed assay set-up can avoid such problems [39,40]. Besides, it allows the detection of a broader spectrum of mutations $[40,41]$ and reduces the costs down to one-quarter.

\section{Allele specific PCR}

The cobas ${ }^{\oplus} 4800$ BRAF V600 test is the only CE-IVD marked test used in this study. The CE-IVD mark indicates that this test meets essential requirements regarding safety, health and environmental protection.

60 out of 82 tumor samples were analyzed with the cobas $^{\ominus}$ BRAF V600 test (Table 1). All samples showed a valid result (100\%). The allele specific PCR used in this test generates an amplicon of 116 base pairs containing codon 600 in exon 15 of the BRAF gene. Amplification curves are shown only for the mutant and the wildtype control but not for the samples analyzed and a nontemplate control is not provided. Data are analyzed when mutant and wildtype controls have a "valid" status. A report is generated automatically and results can be distinguished between "mutation detected" and "mutation not detected". This test is specific for the p.V600E mutation with a reported sensitivity of $\geq 5 \%$ mutated alleles in a background of wildtype alleles [42]. Limit of detection in our preselected cohort was $7 \%$ mutant alleles in a background of wildtype alleles (Table 1 ).

36 of 37 p.V600E mutations were detected with the cobas ${ }^{\oplus}$ $B R A F$ V600 test (97.2\% sensitivity). One case with a borderline frequency of $5 \%$ of mutated alleles using pyrosequencing (Figure 3) could not be detected. But it should be taken into account that we extracted the DNA with our standard inhouse method and not with the recommended kit. This may influence the test results. Furthermore, the marked area on the HE-stained slide contained many lymphocytes diluting the p.V600E alleles. Curry et al. showed an even lower limit of detection of $4.4 \%$ mutated alleles per $1.25 \mathrm{ng} / \mu \mathrm{l}$ on FFPE tissues for the p.V600E mutation [43]. In contrast, LadeKeller et al. performed a dilution series of p.V600E mutated DNA followed by analysis on the cobas $^{\circ} 4800$ BRAF V600 test. This test was not able to detect a p.V600E mutation on the dilution point that theoretically contained $10 \%$ mutant alleles [33].

Analysis have shown cross reactivity with p.V600E2 (>65\% allele frequency), p.V600K (>35\%) and p.V600D (>10\%) but not with p.V600R mutation [43,44]. In our cohort, the cobas $^{\oplus}$ BRAF V600 test showed cross reactivity five times in p.V600K mutated samples containing 59, 61, twice 62 and $64 \%$ of mutated alleles using pyrosequencing. One p.V600K mutation with a frequency of $57 \%$ that is above the described cross reactivity, was not detected by the cobas ${ }^{\odot}$ 4800 BRAF V600 test.

Furthermore, several additional cases with a mutation frequency below the described limit of detection were missed in our study: case 9 showed a frequency of $6.6 \%$ for p.V600K, case $3625 \%$ for the same mutation and case 24 an allele frequency of $46 \%$ for the p.V600E2 mutation (Additional file 1). Case 3, 33 and 38 showed a mutation frequency of 37,42 and $39 \%$ for p.V600R mutation that can not be detected by this kit. This makes an overall failure rate of $13.3 \%$ in our preselected cohort and a failure rate of mutation located in codon 600 of $16.3 \%$. Halait et al. even showed that the cobas $^{\oplus} 4800$ BRAF V600 test failed to detect $19 \%$ of the mutations occurring in codon 600 of the BRAF gene [45]. In the study of Curry et al. $82.3 \%$ of non-p.V600E mutations (p.V600K and p.V600R) were not detected having a tumor content range from $5-45 \%$ and $14 \%$ median mutant alleles. But recent studies showed that even patients with p.V600K, p.V600D and p.V600E2 mutation positive melanomas may benefit from therapy with vemurafenib $[7,9,15,46,47]$. Furthermore, patients with uncommon mutations as p.V600R and double mutations as 
e.g. p.[V600E(;)V600M] treated with dabrafenib showed response based on RECIST (Response Evaluation Criteria in Solid Tumors) criteria and regression of metastatic lesions [15].

As expected, all other mutations evaluated could not be detected by this method (Tables 1 ). $3.8 \%$ of all mutations detected in malignant melanomas are outside of codon 600 of the BRAF gene [5]. To date, there are 121 different missense mutations described for BRAF [6]. Especially the p.L597 mutation (frequency 0.5\%) plays an important role as it seems to be associated with sensitivity to MEK inhibitor therapy with TAK-733 $[48,49]$. To conclude, in its present set-up, this test is not sufficient for the European approval of vemurafenib [50].

\section{Next generation sequencing}

Next generation sequencing allows the sensitive and simultaneous detection of various mutations in different genes in a multiplex approach. 72 out of 82 cases were subjected to next generation sequencing (NGS). Coverage for $B R A F$ exon 15 ranged from 352 to 20174 with a mean coverage of 5015.4. The coverage of the mutation site ranged from 118 to 12002 with a mean coverage of 1934.7. Rechsteiner et al. reported in a cohort of 81 colorectal carcinoma samples a coverage rate from 5139 to 17156 [51]. As the threshold of coverage was set to 100 all samples could be analyzed.

The whole mutational spectrum could be detected by NGS and all cases were analyzed successfully (Additional file 1). The cut-off value defined for reliable mutation detection was set as a frequency of $5 \%$ mutant alleles. With this cut-off all but one mutation were analyzed correctly (98.6\% sensitivity). Case 30 (Figure 3) showed only a $2 \%$ mutant allele frequency in the Integrative Genomic Viewer [6]. Coverage rate using NGS was very low with 181 which may have influenced the results obtained. In the whole cohort the lowest frequency of mutant alleles detected with NGS was 7\% (Additional file 1). This makes a specificity of $100 \%$ for NGS but a sensitivity of $98.6 \%$ (Table 1).

NGS is characterized by a high working load with a lot of hands-on time and high costs. These disadvantages are compensated by the multiplexing possibilities, the broad spectrum of mutations detected and the high sensitivity. Recent publications state that almost $75 \%$ of cancer gene variations may be missed by an approach analyzing only hotspot mutations [52].

The establishment of this rather new method for routine diagnostic is an ongoing process. The expertise in computational biology required to perform clinical NGS is significantly higher than for any other of the established methods. Especially, the result interpretation is challenging: Where to define the cut-off value for a reliable mutation, which spectrum of mutations to report, how to validate and to report the results, how to handle the massive data generated? Standardization and validation of the test procedure and the data interpretation, cost reduction and getting to know the pitfalls of this method are the challenges of the future.

\section{Immunohistochemistry}

Immunohistochemistry (IHC) is characterized by a fast and cheap performance and allows the detection of even small amounts of tumor cells harboring the specific antigen. 49 of the 82 samples were subjected to immunohistochemistry. Staining was homogenous within the tumor cells as shown by other groups before [53]. Figure 1 shows representative immunohistochemical stainings of p.V600E mutation (J) and p.V600K mutation (K) both in a melanoma sample and p.V600R mutation (L) of a colorectal tumor.

Staining with the p.V600E specific monoclonal antibody detected all evaluated p.V600E mutations (100\%). 22 of these p.V600E mutated samples were melanoma and two were colorectal tumors. Colomba et al. described in contrast a IHC failure rate of $7.2 \%$ in a cohort of 111 cases [24] due to equivocal staining.

Furthermore, case 25, showing a double mutation in codon 600 and codon 601 of the BRAF gene was scored negative in IHC (Additional file 1). This is in concordance with the study of Skorokhod et al. (2012) who could not detect the double mutation with the monoclonal VE1 antibody either [54]. Eight cases with non-p.V600E mutation were scored as $1+$ and therefore negative in the IHC (p.V600K, p.L597R/S, p.E586K and p.D594N). Like for the cobas $^{\circ} 4800$ BRAF V600 test this p.V600E specificity constitutes the major limitation of the IHC for routine diagnostics as a single test.

However, the IHC was not completely specific for the p.V600E mutation as cross reactivity was observed in one case with a p.V600R mutation that was scored as $2+$ (Table 1). This is in contrary to most other studies reporting no cross reactivity with non-p.V600E mutations [54-56]. Only Heinzerling et al. (2013) found for one sample an immunohistochemical cross reactivity with p.V600K mutation [57]. Therefore, in our study this method is characterized by $100 \%$ sensitivity but only $98 \%$ specificity (Table 1). Long et al. showed a sensitivity of $97 \%$ and a specificity of $98 \%$ in a cohort of 100 samples [56].

One case of our study highlighted the importance of immunohistochemical staining prior to DNA extraction for mutational analysis. Case 7 was wildtype using Sanger sequencing, HRM, and $\operatorname{cobas}^{\circ} B R A F$ V600 test in the first extraction. NGS showed a p.V600E mutation with a $3 \%$ allele frequency being under our defined threshold. Sections for IHC were cut after the molecular analysis and results were positive with a score of $2+$ by a senior pathologist (H. U. S.). Tumor content increased only slightly 
compared to the first $\mathrm{H} \& \mathrm{E}$ stained slide. Therefore, a second extraction was performed and analysis was repeated. The second extract showed a p.V600E mutation using Sanger sequencing, HRM, NGS as well as cobas ${ }^{\circ}$ $B R A F$ V600 test (Figure 4).

In general, Sanger sequencing needs $2-4$ working days to produce a report. In contrast, HRM is time and cost saving and a major advantage is the prevention of contaminations as HRM is a close-tube process [58,59]. But it only serves as screening method not giving the exact mutational status. Advantages of pyrosequencing are that it is more sensitive than Sanger sequencing (5\% versus $6.6 \%$ in our cohort) and the amount of work is lower compared to Sanger sequencing hence no clean up steps of the PCRproducts is needed $[34,40]$ but result interpretation is more prone to errors. The cobas ${ }^{\oplus} 4800 B R A F$ V600 test is characterized by an easy and fast performance with a low amount of work. Costs are medium compared to the other evaluated methods (Table 1). Immunohistochemistry (IHC) is characterized by a fast and cheap performance and allows the detection of even small amounts of tumor cells harboring the specific antigen but is limited to the detection of p.V600E mutations. NGS should be carefully validated to implement this method into routine diagnostics. At the moment it is only financially feasible when the full capacity of the device is used.

\section{Conclusion}

To conclude, this is so far the only study comparing these five molecular methods with immunohistochemistry. We

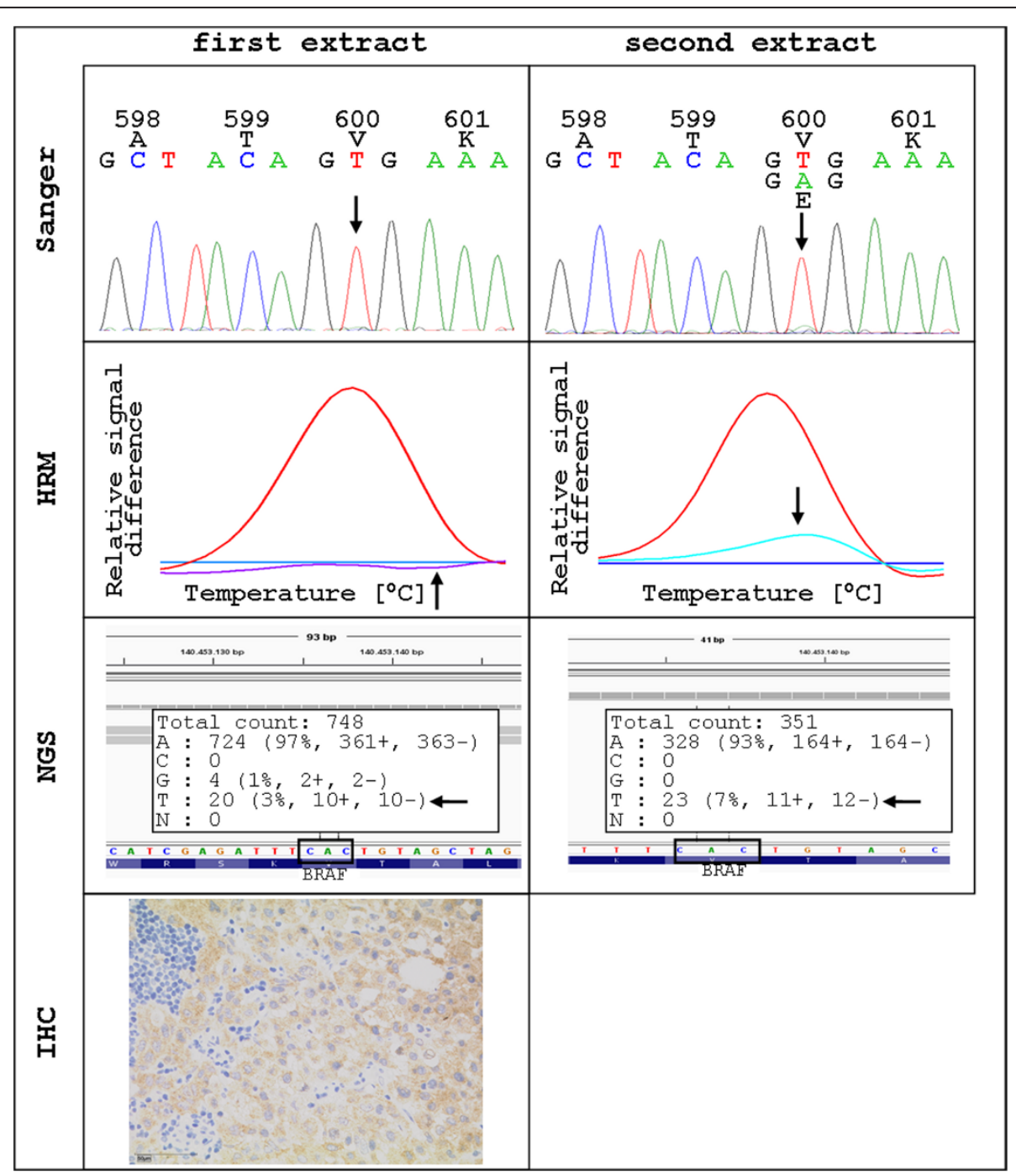

Figure 4 Effects of different extracts on the same sample. DNA from a melanoma sample (case 7) was extracted and showed wildtype results using Sanger, HRM and NGS (3\% mutant allele frequency). In contrast, immunohistochemistry was positive. The second extract exhibited a p.V600E mutation with all evaluated methods. Sanger: Sanger sequencing, HRM: high resolution melting analysis, NGS: next generation sequencing, IHC: immunohistochemistry. 
could show that Sanger sequencing as a well established tool is a reliable method for $B R A F$ mutation analysis with a limit of detection of $6.6 \%$. However, this method has to be replaced by faster and more cost effective methods. The cobas ${ }^{\circ} 4800$ BRAF V600 test has limited utilization as it detects only p.V600E mutations losing $16.3 \%$ of patients eligible for a therapy with vemurafenib. The pyrosequencing approach showed in fact the highest sensitivity in our preselected cohort with a limit of detection of 5\% mutant alleles but exhibited the lowest specificity with $90 \%$ and is prone to errors without using customer designed set-up. In their present set-up, the cobas ${ }^{\circ}$ 4800 BRAF V600 test as well as the therascreen ${ }^{\circ}$ BRAF Pyro Kit are therefore not sufficient for the European approval of vemurafenib because there is a therapeutic option for melanoma patients with any mutation in codon 600 of the BRAF gene [50]. Therefore, we suggest a combination of VE1 antibody staining and HRM for p.V600E mutation analysis combining the lowest detection limit with a fast, reliable method with $100 \%$ sensitivity for routine diagnostics at the moment.

In the near future and with growing experiences, it is an inevitable fact that NGS will replace all established methods for molecular diagnostics. This is based on the high sensitivity and multiplexing options of this method allowing to generate a molecular profile of each tumor sample analyzed.

\section{Additional file}

Additional file 1: Summary of $B R A F$ mutation detection using five different molecular methods compared to immunohistochemistry.

\section{Competing interests}

The authors declare that they have no competing interests.

\section{Authors' contributions}

MAI carried out the molecular analysis and drafted the manuscript. JF established and performed the pyrosequencing analysis whereas KK established the NGS approach and made substantial contributions to the NGS analysis. MS, NK, LT and HUS performed pathological review of clinical material. HUS further analyzed IHC samples and contributed to the manuscript writing. IG analyzed IHC samples as a second reviewer. RB revised the manuscript critically for important intellectual content. SMB. supervised experiments, wrote the paper and revised critically the final manuscript. All authors read and approved the final manuscript.

\section{Acknowledgement}

We appreciate the expert technical assistance of Anna Sotnikov, Susan Zupp and Wiebke Jeske.

\section{Author details}

${ }^{1}$ Institute of Pathology, University of Cologne, Medical Centre, Cologne, Germany. ${ }^{2}$ Institute of Dermatology, University of Cologne, Medical Centre, Cologne, Germany. ${ }^{3}$ Institute of Pathology, Ortenau-Hospital Lahr-Ettenheim, Lahr-Ettenheim, Germany. ${ }^{4}$ Current address: Gerhard-Domagk-Institute of Pathology, University of Münster, Medical Centre, Münster, Germany. ${ }^{5}$ Current address: Institute of Pathology, University Medical Centre, Göttingen, Germany.
Received: 4 September 2013 Accepted: 8 January 2014

Published: 10 January 2014

\section{References}

1. Robinson MJ, Cobb MH: Mitogen-activated protein kinase pathways. Curr Opin Cell Biol 1997, 9(2):180-186.

2. Dhomen $N$, Marais R: BRAF signaling and targeted therapies in melanoma. Hematol Oncol Clin North Am 2009, 23(3):529-545. ix.

3. Xing M: BRAF mutation in thyroid cancer. Endocr Relat Cancer 2005, 12(2):245-262.

4. Davies H, Bignell GR, Cox C, Stephens P, Edkins S, Clegg S, Teague J, Woffendin H, Garnett MJ, Bottomley W, Davis N, Dicks E, Ewing R, Floyd Y, Gray K, Hall S, Hawes R, Hughes J, Kosmidou V, Menzies A, Mould C, Parker A, Stevens C, Watt S, Hooper S, Wilson R, Jayatilake H, Gusterson BA, Cooper C, Shipley J, et al: Mutations of the BRAF gene in human cancer. Nature 2002, 417(6892):949-954.

5. Wellcome Trust Sanger Institute: Catalogue of somatic mutations in cancer (COSMIC) database. www.sanger.ac.uk/genetics/CGP/cosmic.

6. Thorvaldsdóttir H, Robinson JT, Mesirov JP: Integrative Genomics Viewer (IGV): high-performance genomics data visualization and exploration. Briefings in Bioinformatics 2012, http://dx.doi.org/10.1093/bib/bbs017.

7. Rubinstein JC, Sznol M, Pavlick AC, Ariyan S, Cheng E, Bacchiocchi A, Kluger HM, Narayan D, Halaban R: Incidence of the V600K mutation among melanoma patients with BRAF mutations, and potential therapeutic response to the specific BRAF inhibitor PLX4032. J Trans/ Med 2010, 8:67.

8. Flaherty KT, Puzanov I, Kim KB, Ribas A, McArthur GA, Sosman JA, O'Dwyer PJ, Lee RJ, Grippo JF, Nolop K, Chapman PB: Inhibition of mutated, activated BRAF in metastatic melanoma. N Engl J Med 2010, 363(9):809-819.

9. Chapman PB, Hauschild A, Robert C, Haanen JB, Ascierto P, Larkin J, Dummer R, Garbe C, Testori A, Maio M, Hogg D, Lorigan P, Lebbe C, Jouary T, Schadendorf D, Ribas A, O'Day SJ, Sosman JA, Kirkwood JM, Eggermont AM, Dreno B, Nolop K, Li J, Nelson B, Hou J, Lee RJ, Flaherty KT, McArthur GA: Improved survival with vemurafenib in melanoma with BRAF V600E mutation. N Engl I Med 2011, 364(26):2507-2516.

10. Halaban R, Zhang W, Bacchiocchi A, Cheng E, Parisi F, Ariyan S, Krauthammer M, McCusker JP, Kluger Y, Sznol M: PLX4032, a selective BRAF(V600E) kinase inhibitor, activates the ERK pathway and enhances cell migration and proliferation of BRAF melanoma cells. Pigment Cell Melanoma Res 2010, 23(2):190-200.

11. Yang H, Higgins B, Kolinsky K, Packman K, Go Z, lyer R, Kolis S, Zhao S, Lee R, Grippo JF, Schostack K, Simcox ME, Heimbrook D, Bollag G, Su F: RG7204 (PLX4032), a selective BRAFV600E inhibitor, displays potent antitumor activity in preclinical melanoma models. Cancer Res 2010, 70(13):5518-5527.

12. Ascierto PA, Kirkwood JM, Grob JJ, Simeone E, Grimaldi AM, Maio M, Palmieri G, Testori A, Marincola FM, Mozzillo N: The role of BRAF V600 mutation in melanoma. J Trans/ Med 2012, 10:85.

13. Fisher R, Larkin J: Vemurafenib: a new treatment for BRAF-V600 mutated advanced melanoma. Cancer Manag Res 2012, 4:243-252.

14. Falchook GS, Long GV, Kurzrock R, Kim KB, Arkenau TH, Brown MP, Hamid O, Infante JR, Millward M, Pavlick AC, O'Day SJ, Blackman SC, Curtis CM, Lebowitz P, Ma B, Ouellet D, Kefford RF: Dabrafenib in patients with melanoma, untreated brain metastases, and other solid tumours: a phase 1 dose-escalation trial. Lancet 2012, 379(9829):1893-1901.

15. Ponti G, Pellacani G, Tomasi A, Gelsomino F, Spallanzani A, Depenni R, Al Jalbout S, Simi L, Garagnani L, Borsari S, Conti A, Ruini C, Fontana A, Luppi G: The somatic affairs of BRAF: tailored therapies for advanced malignant melanoma and orphan non-V600E (V600R-M) mutations. J Clin Pathol 2013, 66(5):441-445.

16. Klein O, Clements A, Menzies AM, O'Toole S, Kefford RF, Long GV: BRAF inhibitor activity in V600R metastatic melanoma. Eur J Cancer 2013, 49(5):1073-1079.

17. Flaherty $K T$, Infante JR, Daud A, Gonzalez R, Kefford RF, Sosman J, Hamid O, Schuchter L, Cebon J, Ibrahim N, Kudchadkar R, Burris HA 3rd, Falchook G, Algazi A, Lewis K, Long GV, Puzanov I, Lebowitz P, Singh A, Little S, Sun P, Allred A, Ouellet D, Kim KB, Patel K, Weber J: Combined BRAF and MEK inhibition in melanoma with BRAF V600 mutations. N Engl J Med 2012, 367(18):1694-1703. 
18. Wan PT, Garnett MJ, Roe SM, Lee S, Niculescu-Duvaz D, Good VM, Jones CM, Marshall CJ, Springer CJ, Barford D, Marais R: Mechanism of activation of the RAF-ERK signaling pathway by oncogenic mutations of B-RAF. Cell 2004, 116(6):855-867.

19. Ji H, Wang Z, Perera SA, Li D, Liang MC, Zaghlul S, McNamara K, Chen L, Albert M, Sun Y, Al-Hashem R, Chirieac LR, Padera R, Bronson RT, Thomas RK, Garraway LA, Janne PA, Johnson BE, Chin L, Wong KK: Mutations in BRAF and KRAS converge on activation of the mitogen-activated protein kinase pathway in lung cancer mouse models. Cancer Res 2007, 67(10):4933-4939.

20. Dankort D, Filenova E, Collado M, Serrano M, Jones K, McMahon M: A new mouse model to explore the initiation, progression, and therapy of BRAFV600E-induced lung tumors. Genes Dev 2007, 21(4):379-384

21. Paik PK, Arcila ME, Fara M, Sima CS, Miller VA, Kris MG, Ladanyi M, Riely GJ: Clinical characteristics of patients with lung adenocarcinomas harboring BRAF mutations. J Clin Oncol 2011, 29(15):2046-2051.

22. Oxnard GR, Binder A, Janne PA: New targetable oncogenes in non-smallcell lung cancer. J Clin Oncol 2013, 31(8):1097-1104.

23. Sen B, Peng S, Tang X, Erickson HS, Galindo H, Mazumdar T, Stewart DJ, Wistuba I, Johnson FM: Kinase-impaired BRAF mutations in lung cancer confer sensitivity to dasatinib. Sci Trans/ Med 2012, 4(136):136ra-170.

24. Colomba E, Helias-Rodzewicz Z, Von Deimling A, Marin C, Terrones N, Pechaud D, Surel S, Cote JF, Peschaud F, Capper D, Blons H, Zimmermann U, Clerici T, Saiag P, Emile JF: Detection of BRAF p.V600E mutations in melanomas: comparison of four methods argues for sequential use of immunohistochemistry and pyrosequencing. J Mol Diagn 2013, 15(1):94-100.

25. Tol J, Dijkstra JR, Vink-Borger ME, Nagtegaal ID, Punt CJ, Van Krieken JH, Ligtenberg MJ: High sensitivity of both sequencing and real-time PCR analysis of KRAS mutations in colorectal cancer tissue. J Cell Mol Med 2010, 14(8):2122-2131.

26. Eckhart L, Bach J, Ban J, Tschachler E: Melanin binds reversibly to thermostable DNA polymerase and inhibits its activity. Biochem Biophys Res Commun 2000, 271(3):726-730.

27. Carbonell P, Turpin MC, Torres-Moreno D, Molina-Martinez I, Garcia-Solano J, Perez-Guillermo M, Conesa-Zamora P: Comparison of allelic discrimination by dHPLC, HRM, and TaqMan in the detection of BRAF mutation V600E. J Mol Diagn 2011, 13(5):467-473.

28. Monzon FA, Ogino S, Hammond ME, Halling KC, Bloom K, Nikiforova MN: The role of KRAS mutation testing in the management of patients with metastatic colorectal cancer. Arch Pathol Lab Med 2009, 133(10):1600-1606.

29. Ney JT, Froehner S, Roesler A, Buettner R, Merkelbach-Bruse S: High-resolution melting analysis as a sensitive prescreening diagnostic tool to detect KRAS, BRAF, PIK3CA, and AKT1 mutations in formalin-fixed, paraffin-embedded tissues. Arch Pathol Lab Med 2012, 136(9):983-992.

30. Balic M, Pichler M, Strutz J, Heitzer E, Ausch C, Samonigg H, Cote RJ, Dandachi N: High quality assessment of DNA methylation in archival tissues from colorectal cancer patients using quantitative high-resolution melting analysis. J Mol Diagn 2009, 11(2):102-108.

31. Do H, Dobrovic A: Dramatic reduction of sequence artefacts from DNA isolated from formalin-fixed cancer biopsies by treatment with uracil- DNA glycosylase. Oncotarget 2012, 3(5):546-558.

32. Marchetti A, Felicioni L, Buttitta F: Assessing EGFR mutations. N Engl J Med 2006, 354(5):526-528. author reply 526-528.

33. Lade-Keller J, Romer KM, Guldberg P, Riber-Hansen R, Hansen LL, Steiniche T, Hager $H$, Kristensen LS: Evaluation of BRAF mutation testing methodologies in formalin-fixed, paraffin-embedded cutaneous melanomas. J Mol Diagn 2013, 15(1):70-80.

34. Tsiatis AC, Norris-Kirby A, Rich RG, Hafez MJ, Gocke CD, Eshleman JR, Murphy KM: Comparison of Sanger sequencing, pyrosequencing, and melting curve analysis for the detection of KRAS mutations: diagnostic and clinical implications. J Mol Diagn 2010, 12(4):425-432.

35. Su F, Viros A, Milagre C, Trunzer K, Bollag G, Spleiss O, Reis-Filho JS, Kong X, Koya RC, Flaherty KT, Chapman PB, Kim MJ, Hayward R, Martin M, Yang H, Wang Q, Hilton H, Hang JS, Noe J, Lambros M, Geyer F, Dhomen N, Niculescu-Duvaz I, Zambon A, Niculescu-Duvaz D, Preece N, Robert L, Otte NJ, Mok S, Kee D, et al: RAS mutations in cutaneous squamous-cell carcinomas in patients treated with BRAF inhibitors. N Engl J Med 2012, 366(3):207-215

36. Oberholzer PA, Kee D, Dziunycz P, Sucker A, Kamsukom N, Jones R, Roden C, Chalk CJ, Ardlie K, Palescandolo E, Piris A, MacConaill LE, Robert C, Hofbauer GF, McArthur GA, Schadendorf D, Garraway LA: RAS mutations are associated with the development of cutaneous squamous cell tumors in patients treated with RAF inhibitors. J Clin Oncol 2012, 30(3):316-321

37. Gong M, Foo SH, Lin L, Liu ET, Gharizadeh B, Goel S: Pyrosequencing enhancement for better detection limit and sequencing homopolymers. Biochem Biophys Res Commun 2010, 401(1):117-123.

38. Shen S, Qin D: Pyrosequencing data analysis software: a useful tool for EGFR, KRAS, and BRAF mutation analysis. Diagn Pathol 2012, 7:56.

39. Chen G, Olson MT, O'Neill A, Norris A, Beierl K, Harada S, Debeljak M, Rivera-Roman K, Finley S, Stafford A, Gocke CD, Lin MT, Eshleman JR: A virtual pyrogram generator to resolve complex pyrosequencing results. J Mol Diagn 2012, 14(2):149-159.

40. Skorokhod A, Helmbold P, Brors B, Schirmacher P, Enk A, Penzel R: Automated universal BRAF state detection within the activation segment in skin metastases by pyrosequencing-based assay U-BRAF(V600.). PLoS One 2013, 8(3):e59221.

41. Spittle C, Ward MR, Nathanson KL, Gimotty PA, Rappaport E, Brose MS Medina A, Letrero R, Herlyn M, Edwards RH: Application of a BRAF pyrosequencing assay for mutation detection and copy number analysis in malignant melanoma. J Mol Diagn 2007, 9(4):464-471.

42. Lopez-Rios F, Angulo B, Gomez B, Mair D, Martinez R, Conde E, Shieh F, Vaks J, Langland R, Lawrence HJ, de Castro DG: Comparison of testing methods for the detection of BRAF V600E mutations in malignant melanoma: pre-approval validation study of the companion diagnostic test for vemurafenib. PLoS One 2013, 8(1):e53733.

43. Curry JL, Torres-Cabala CA, Tetzlaff MT, Bowman C, Prieto VG: Molecular platforms utilized to detect BRAF V600E mutation in melanoma. Semin Cutan Med Surg 2012, 31(4):267-273.

44. Anderson S, Bloom KJ, Vallera DU, Rueschoff J, Meldrum C, Schilling R, Kovach B, Lee JR, Ochoa P, Langland R, Halait H, Lawrence HJ, Dugan MC Multisite analytic performance studies of a real-time polymerase chain reaction assay for the detection of BRAF V600E mutations in formalin-fixed, paraffin-embedded tissue specimens of malignant melanoma. Arch Pathol Lab Med 2012, 136(11):1385-1391.

45. Halait H, Demartin K, Shah S, Soviero S, Langland R, Cheng S, Hillman G, Wu L, Lawrence HJ: Analytical performance of a real-time PCR-based assay for V600 mutations in the BRAF gene, used as the companion diagnostic test for the novel BRAF inhibitor vemurafenib in metastatic melanoma. Diag Mol Path 2012, 21(1):1-8

46. Sosman JA, Kim KB, Schuchter L, Gonzalez R, Pavlick AC, Weber JS, McArthur GA Hutson TE, Moschos SJ, Flaherty KT, Hersey P, Kefford R, Lawrence D, Puzanov I, Lewis KD, Amaravadi RK, Chmielowski B, Lawrence HJ, Shyr Y, Ye F, Li J, Nolop KB, Lee RJ, Joe AK, Ribas A: Survival in BRAF V600-mutant advanced melanoma treated with vemurafenib. N Engl J Med 2012, 366(8):707-714.

47. Nikolaou VA, Stratigos AJ, Flaherty KT, Tsao H: Melanoma: new insights and new therapies. J Invest Dermatol 2012, 132(3 Pt 2):854-863.

48. Dong Q, Dougan DR, Gong X, Halkowycz P, Jin B, Kanouni T, O'Connell SM, Scorah N, Shi L, Wallace MB, Zhou F: Discovery of TAK-733, a potent and selective MEK allosteric site inhibitor for the treatment of cancer. Bioorg Med Chem Lett 2011, 21(5):1315-1319.

49. Dahlman KB, Xia J, Hutchinson K, Ng C, Hucks D, Jia P, Atefi M, Su Z, Branch S, Lyle PL, Hicks DJ, Bozon V, Glaspy JA, Rosen N, Solit DB, Netterville $J$, Vnencak-Jones CL, Sosman JA, Ribas A, Zhao Z, Pao W: BRAF(L597) mutations in melanoma are associated with sensitivity to MEK inhibitors. Cancer Discov 2012, 2(9):791-797.

50. da Rocha DS, Salmonson T, van Zwieten-Boot B, Jonsson B, Marchetti S, Schellens JH, Giuliani R, Pignatti F: The European Medicines Agency review of vemurafenib (Zelboraf(R)) for the treatment of adult patients with BRAF V600 mutation-positive unresectable or metastatic melanoma: summary of the scientific assessment of the Committee for Medicinal Products for Human Use. Eur J Cancer 2013, 49(7):1654-1661.

51. Rechsteiner M, von Teichman A, Ruschoff JH, Fankhauser N, Pestalozzi B, Schraml P, Weber A, Wild P, Zimmermann D, Moch H: KRAS, BRAF, and TP53 deep sequencing for colorectal carcinoma patient diagnostics. J Mol Diagn 2013, 15(3):299-311.

52. Ross JS, Cronin M: Whole cancer genome sequencing by next-generation methods. Am J Clin Pathol 2011, 136(4):527-539.

53. Capper D, Berghoff AS, Magerle M, Ilhan A, Wohrer A, Hackl M, Pichler J, Pusch S, Meyer J, Habel A, Petzelbauer P, Birner P, von Deimling A, Preusser M: Immunohistochemical testing of BRAF V600E status in 1,120 tumor tissue samples of patients with brain metastases. Acta Neuropathol 2012, 123(2):223-233. 
54. Skorokhod A, Capper D, von Deimling A, Enk A, Helmbold P: Detection of BRAF V600E mutations in skin metastases of malignant melanoma by monoclonal antibody VE1. J Am Acad Dermatol 2012, 67(3):488-491.

55. Busam KJ, Hedvat C, Pulitzer M, von Deimling A, Jungbluth AA: Immunohistochemical analysis of BRAF(V600E) expression of primary and metastatic melanoma and comparison with mutation status and melanocyte differentiation antigens of metastatic lesions. Am J Surg Pathol 2013, 37(3):413-420.

56. Long GV, Wilmott JS, Capper D, Preusser M, Zhang YE, Thompson JF, Kefford RF, von Deimling A, Scolyer RA: Immunohistochemistry is highly sensitive and specific for the detection of V600E BRAF mutation in melanoma. Am J Surg Pathol 2013, 37(1):61-65.

57. Heinzerling L, Kuhnapfel S, Meckbach D, Baiter M, Kaempgen E, Keikavoussi P, Schuler G, Agaimy A, Bauer J, Hartmann A, Kiesewetter F, Schneider-Stock R: Rare BRAF mutations in melanoma patients: implications for molecular testing in clinical practice. Br J Cancer 2013, 108(10):2164-2171.

58. Reed GH, Kent JO, Wittwer CT: High-resolution DNA melting analysis for simple and efficient molecular diagnostics. Pharmacogenomics 2007, 8(6):597-608.

59. Jancik S, Drabek J, Berkovcova J, Xu YZ, Stankova M, Klein J, Kolek V, Skarda J, Tichy T, Grygarkova I, Radzioch D, Hajduch M: A comparison of direct sequencing, pyrosequencing, high resolution melting analysis, TheraScreen DxS, and the K-ras StripAssay for detecting KRAS mutations in non small cell lung carcinomas. J Exp Clin Cancer Res 2012, 31:79.

doi:10.1186/1471-2407-14-13

Cite this article as: Ihle et al: Comparison of high resolution melting analysis, pyrosequencing, next generation sequencing and immunohistochemistry to conventional Sanger sequencing for the detection of p.V600E and non-p.V600E BRAF mutations. BMC Cancer 2014 14:13.

\section{Submit your next manuscript to BioMed Central and take full advantage of:}

- Convenient online submission

- Thorough peer review

- No space constraints or color figure charges

- Immediate publication on acceptance

- Inclusion in PubMed, CAS, Scopus and Google Scholar

- Research which is freely available for redistribution 